\title{
Ophthalmic Nerve
}

National Cancer Institute

\section{Source}

National Cancer Institute. Ophthalmic Nerve. NCI Thesaurus. Code C33215.

The first and smallest of three divisions of the trigeminal nerve, which carries only sensory fibers supplying innervation to the forehead, scalp, lacrimal gland, eye, and side of the nose. 